\title{
Investing in Lean to Improve Basic Capabilities: A strategy for System Supply?
}

\author{
Inga-Lill Carlsson ${ }^{1}$ (D) Håkan Aronsson² ${ }^{\text {(D) }}$ \\ ${ }^{1}$ Linköping University (Sweden) \\ ${ }^{2}$ Department of Management and Engineering (IEI) / Logistics and Quality Management (LOGQ), \\ Linköping University (Sweden) \\ inga-lill.carlsson@,aycee.se, hakan.aronsson@,liu.se
}

Received: November 2016

Accepted: January 2017

\section{Abstract:}

Purpose: This paper describes the perceived effects of implementing lean production in a Swedish SME contract manufacturer. Especially focused are the effects on, and possible tradeoffs between, cost-efficiency and flexibility.

Design/methodology/approach: SME suppliers need basic capabilities of qualitative production performance as stepping-stones to develop more system supplier capabilities for added customer value. Development of stable production processes is seen as a way to reach stable basic performance, efficient and with higher resource utilization. Quality is a precursor to delivery performance as well as to cost reduction and flexibility. This is a longitudinal single case study of a SME supplier striving to become a system supplier. Two main sources of data collection are used: interviews and the main author's presence as employee and business developer, participating in and following up the ongoing change process.

Findings: Analyzing the development over time illustrated the importance of context and content for the change process. Two specific findings appeared: (1) An initial effect was an important "eye-opener" for the balance between cost efficiency and flexibility in the organization. (2) Process orientation, as the basis of both lean and agile approaches, allows many improvements without any conflicts or trade-offs between these two goals. Stability in the production leads to 
increased controllability, initially resulting in both higher cost-efficiency and higher flexibility. As the organization develops however, strategic considerations relating to the chosen market strategy might occur: cost leadership or differentiation.

Research limitations/implications: These results reflect the experiences of one SME supplier and further studies are needed for generalizability.

Originality/value: The study increases the understanding of how a SME may develop stable processes in its different supplier-customer contexts. The study points at some necessary basic components of this process approach as a first step for the transition to system supplier.

Keywords: SME, system supplier capability, lean production, agility, stable processes

\section{Introduction}

Supply chains may be dominated by large organizations but they are reliant on a host of SMEs that contribute to value-creating activities. When large international companies change their production structure the effects ripples throughout their supplier networks. SME contract manufacturers are normally producing for several different industrial customers. Often they have no products of their own and their manufacturing processes are seldom unique. A contract manufacturer might be specialized as component supplier, i.e. a supplier who delivers a well-defined component or service, produced in one or a few process steps, often with a highly automated production and a slim organization. Such suppliers frequently experience intense price competition. In contrast, a system supplier is here defined as a contract manufacturer with an overall responsibility for the functionality of a product or a system of assembled components, produced in several process steps, and the resulting liability for purchase of material and services. These firms need to manage a wider range of sourcing and production facilities and services, e.g. managing production forecasts throughout the supply chain, and warehousing for customers (Zhang, Vonderembse \& Lim, 2005).

The extensive competition raises demands on small system suppliers and their supply chains to utilize their limited resources in the best ways. Stable performance as regards quality, delivery precision and cost reductions are basic capabilities required by most suppliers. The concept of lean production has become a popular way to try to achieve cost efficiency. This is an element of survival, efficiently producing the right things at the right time, offering attractive prices to the customers and creating enough yields for further investments. At the same time, flexibility to align with changing demands is also very important, emphasizing the ability of the strategic management to adapt, integrate and reconfigure the available 
organizational skills and resources accordingly (Meade \& Sarkis, 1999). Flexibility is often associated with an agile approach, as opposed to lean production.

The aim here is to see if implementing lean production affects the system capabilities, especially focusing on managing these supposedly conflicting goals of cost efficiency and flexibility in the supply chain. The question posed is:

Would implementation of lean improve the capabilities of a SME supplier to meet basic demands and add system supplier capabilities, especially focusing cost efficiency and flexibility?

\section{Theoretic Framework}

Lean production is widely recognized as a way to reduce costs through methods as JIT (just-in-time) with very small buffers and levelling production rates, and to increase quality through widened employee roles and responsibilities (Sugimori, Kusunoki, Cho \& Uchikawa, 1977; Hines, Holweg \& Rich, 2004; Bhasin \& Burcher, 2006). Agility is a similar philosophy though more aiming at increasing flexibility (Meade \& Sarkis, 1999; Narasimhan, Swink \& Kim, 2006).

According to Narasimhan et al. (2006) lean production aim to increase internal efficiency by eliminating waste focusing low cost, while agile production focus on flexibility through efficient response to uncertainties and changing conditions. The authors suggest that "while the pursuit of agility might presume leanness, pursuit of leanness might not presume agility" (ibid. pp. 440) and they claim that there is a considerable overlap between the two concepts when looking at them from the practice perspective. Hallgren and Olhager (2009) conclude that properly applied lean principles may lead to improvements in many operational performances, but when comparing lean and agile manufacturing they also find that some distinctly different capabilities are fostered.

The demands on a supplier when developing as a system supplier are changing. The basic requirements of quality, delivery precision, and efficient production tighten and the suppliers are expected to proactively meet rapid changes in a customer's order flow. A challenge for the supplier is to determine which capabilities are needed to manage these changing conditions. 


\subsection{Efficiency and Flexibility}

Flexibility is often said to be an important quality to a supplier, but might mean different things: it is often linked to risks and uncertainties, and a dynamic efficiency to handle these. Klein (1984) distinguishes between two types of efficiency: static efficiency (routines to combine given inputs in an optimal way) and dynamic efficiency (flexibly managing processes to change production functions in profitable directions). Carlsson (1989) describes a dynamically efficient firm as being quick to respond to or generate new ideas and taking advantage of them before the competitors do. Klein (1984) also differentiates between two types of flexibility, both stressing quick responses but with different aims and directions. Type I flexibility aims at quick responses to changed market conditions, e.g. volumes, while Type II is about being alert to and make the best use of opportunities for new products and processes. Carlsson (1989) sets a time perspective:

- operational (short-term) flexibility where built-in procedures allow variable sequencing, scheduling, etc.;

- tactical (medium-term) flexibility where the built-in technology, i.e. organization and production equipment, allow changes in production rate, product mix or design; and

- strategic (long-term) flexibility that "reflects how the firm positions itself with respect to a menu of choices for the future" (ibid. p. 187).

He claims that a flexible organization requires both the structure and the people to be flexible - an important issue for the top management to recognize, especially as Hallgren and Olhager (2009) conclude that high levels of flexibility contribute to competitive value through better operational performance.

There are inevitable trade-offs when implementing a given strategy requires long-term commitments through investments in plants, equipment, and capabilities (Skinner 1996, Hayes \& Pisano, 1996; Clark, 1996; Adler, Goldoftas \& Levine, 1999). Firms cannot be experts on everything but must handle different trade-offs, such as efficiency vs. flexibility (March, 1991; Levinthal \& March, 1993; Adler et al., 1999). However, the increasingly competitive environments force firms to strive for both. 


\section{Method and Purpose}

This paper refers to a single case study covering the period 2008-2013. The choice of the case company was governed by the fact that the focal supplier strives to become a system supplier. It was also important that the main author has been employed and a member of the executive group in this company for more than 15 years, where one of the main duties include business development issues. This also facilitated access to relevant data of all kinds. There are thus two main sources for data collection: interviews and the main author's presence and participation in the ongoing change process. In the study nine interviews were carried out with the strategic management of the focal supplier (lean implementation manager, sales manager, purchasing manager, production manager, CEO, group CEO) as well as with some of the operative management (quality manager, production leaders). The interviews were semi-structured and took about 60-90 minutes each, with transcriptions acknowledged by each interviewee.

The purpose was to establish what intentions and expectations preceded the investment in lean implementation, and the experienced effects on the internal production system and the supply chain. Interviewing both strategic and operative managers reduces the risk of "wishful thinking" from the strategic management. As the interviewees after two years of implementation have considerably more understanding of the lean concept, another important aspect is their expectations of the further development of the system. Having followed the different phases of the lean implementation rather closely also made it possible to ask clarifying attendant questions.

The study builds primarily on the perceptions of the interviewees about the effects on, and possible trade-offs between, cost-efficiency and flexibility. There are no key performance indicators measuring the development of these factors over time and thus no measurable effects directly linked to the lean implementation. The follow-up after five years covers organizational changes and the economic development of the company, built on operational data and discussions in the management group. 


\section{The focal Supplier}

The contract manufacturer, with about 120 employees, is in 2013 one out of four collaborating mechanical suppliers in a privately owned industrial group. The company describes itself as a complete supplier of mechanics and strives to be included as a production partner from a relatively early stage in the product development process, a goal achieved towards some customers. The cooperation within the group enables the company to widen its offer, an important means evolving in a role as system supplier. Targeted business sectors are medical technology, electronics/instruments, telecom, defense industry and engineering industry, with a limited number of mainly large, internationally active companies with manufacturing units in Sweden.

The CEO found the production process of the company too static:

It is not possible to be flexible through a normal process with long lead times and many process steps. Regular practices / processes need to be built to meet the demands we have on us. Today, our handling of a customer with changing needs is quite rigid - "the production is fully occupied". Changes are made on other customers' expense.

\subsection{The Supplier Context: Different Customers - Different Conditions}

The focal supplier has customers with different product life cycles, different volumes, different sales argument, seasonal variations as well as variations due to fluctuations in the market. These customers need to be handled with different logic as regards for example purchasing and production planning, and stock keeping. The risks in each business vary very much, influencing the view of cost and flexibility. A few examples:

Volume production for telecom is an example of a very price-focused business, very dependent upon suppliers that can guarantee continuous deliveries although the volume fluctuations can be very large with rapidly changing forecasts. As the lead-times of some expensive components are long and as the components are sometimes in short supply, this requires large stocks. In addition, as product changes are relatively frequent, the risk for obsolescence is obvious. This is an area where the pressure to reduce leadtimes, primarily to increase cost efficiency, is very pronounced. Customer demands for flexibility might be stressed by penalty clauses. The high volume segment of the telecom business is now a closed chapter for the focal supplier. The ever-increased cost focus would have required large investments in automated machinery and still no guarantees for long-term business. 
The automation business is more stable and predictable. The share of purchased material and components is high and the customers are very demanding as regards cost-cut in purchasing as well as in production. Castings are expensive, costly to transport, and often with large quality costs involved, as some defects cannot be detected until production has started. As import from low cost countries in Asia increases, the stocks tend to grow in order to handle these goods. Agreements enable flexibility, but the first priority is cost reduction.

Within the business of medical devices the importance of quality is extra pronounced, with strict documentation demands. The customers are often able to produce reliable forecasts, focusing delivery precision, while the price pressure is slightly less important. The products have a relatively long lifespan, there are no exceptional lead-times of the materials, and the possibilities of planning from customer forecasts are good. The first priority tends to be flexibility to increasing volumes - the cost effects might be more focused when the volumes are decreasing.

The first choice for a system supplier and an increasingly important activity for the focal supplier is to be able to participate early in customers' product development projects. Such customer collaboration requires total flexibility, continuous adaptation, almost nothing can be standardized except perhaps the process in itself. Time is crucial. Flexibility within the organization and towards its suppliers is what counts; cost is not a main concern here. It is very expensive, but these services and products are not price sensitive. The margins are good, and it is important to learn as much as possible about the product specifications and customer requirements in order to optimize the production process in the next step. The problem with these activities might be the accessibility to machine capacity. To coordinate these orders for one or a few products, time-consuming through long set-up times, demanding highly qualified operators and causing much disturbance in the flow, is a delicate task. What routines need to be coordinated: work of individuals, deliveries between production units, certain suppliers, or the whole flow? Another situation requiring flexibility could be spare parts production. This often concerns very small batches, with fixed lead-times and prices in long-term customer agreements.

\subsection{The Supplier Change Process: Implementing Lean Production}

There was no strategic agreement to forego the decision to implement lean production, but rather a will to seize the opportunity to get support through the consultancy of "Produktionslyftet" - a broad collaboration project between national foundations, trade unions and several universities. A logistics project, focused on timely deliveries some years previously, had increased the understanding of planning processes but the preunderstanding and anticipated effects of the lean implementation varied. The management had a good understanding of the effects of some of the lean tools, mainly those affecting 
productivity and quality, while the understanding of "the lean philosophy" was negligible. Some of the production leaders expressed a hesitant attitude: "Yet another improvement project..."

Thus, the focal supplier decided in 2008 to implement lean production in order to secure the future survival of the company through strengthening its competitiveness. This was seen as a way to render the business more effective and to utilize the resources better. Customers' demands on quality, delivery precision, productivity and flexibility had to be fulfilled. Clearly, the focus was on the three first values with flexibility only mentioned in the preface of the focal supplier's Production System (MPS). Flexibility here mainly means responsiveness to volume changes and the setting up of new products (Type I flexibility according to Klein, 1984). The company claims to prioritize safety first, then quality, delivery deadlines, and economy - in that order. Different organizational groups stepwise compiled and processed the company values and its lean principles.

\subsection{Findings After Two Years}

\subsubsection{Content}

After two years of implementing lean all of the interviewees pointed out some positive effects perceived: improved orderliness, increased engagement and better atmosphere, and a greater willingness to adapt and change working methods. Other important aspects were to understand customer demands, and the attitude of the personnel. Many employees had stepped forward and grown in their roles. Many "ahainsights" emanated from lean education and information, and brought about a broad understanding within the organization. The management considered this very important for the future development, and a way to strengthen the competitive advantage of the company (cf. Vastag, 2000).

Specific effects were mentioned, such as a large number of accomplished improvements originating from the improvement groups, reduction of wastes, time savings, more flexibility through smaller batches in production, capital rationalization effects, increased productivity and increased asset utilization, better-structured meetings, and more. However, there was also a common understanding that there was a lot left to do to make these effects permanent, and to develop the lean concept.

The expectations of potential further effects were partly more of what had already been achieved: e.g. more elimination of waste, still better asset utilization, more productivity increase, better effect from improvement groups. However, the anticipated effects were wider than that. The need and possibilities for administrative improvements were a common understanding. It would be necessary to weave more standardization, systematization and simplification into every-day activities all over the organization. To develop metaroutines for standardized problem solving would make it possible to 
reduce "firefighting" activities and re-use solutions, thereby reducing cost and as a secondary effect increase flexibility.

The operational performance priorities were of course important - cost efficiency, quality ("right from me"), increased delivery precision, and increased flexibility. None of the interviewees saw any potential clash of interests between cost efficiency and flexibility - these were goals and effects often mentioned in the same breath. The estimated potential for improvements here were very large, within existing capacity. An evident effect of the lean implementation was the emergent understanding across the organization of the balance between these two improvement areas.

The most important thing to attend to for increased flexibility seemed to be flow planning, mentioned by almost all the interviewees. To agree on the planning principles was important in order to utilize the machines efficiently and minimize "bottle-necks" in the production and to avoid firefighting. Standardized flows and stable production processes were considered necessary, visualizing important flows and possibilities to increase accessibility. Competence, collaboration and cross-functionality were mentioned, required to allocate the right resources at every occasion, for example to shorten lead-times, and to increase supplier collaboration in competence/capacity combinations. A business strategy to coordinate the resources would help. The discussion of overcapacity to increase flexibility existed, but the common opinion seemed to be that much could be achieved through better planning. This was a change brought about through understanding the potential of lean - seeing the possibility to increase the asset utilization considerably (and estimating increased productivity by $20-50$ percent).

\subsubsection{Process}

The suggested ways to achieve the improvements varied - stressing for example flow planning and improved supplier communication to shorten the lead-times. The tools and values mostly referred to were 5S (Sort, Set in Order, Shine, Standardize, and Sustain; commented by the CEO: "wonderfully visual, engages many and is easily understood"), SMED (Single Minute Exchange of Dies), VFA (Value Flow Analysis), improvement groups and continuous improvement.

The improvement groups were considered very important for the future development. All the interviewees emphasized that for these groups to function at their best the leadership at all levels in the company need to be forerunners of the MPS. Leaders need to develop a more coaching attitude, with individualized competence development, delegated authorities, clear and distributed goals, work environments, cross-functionality and work processes with built-in quality in focus. Trust was stressed: 
e.g. that the leaders encourage and trust the operators' judgment to "pull the string" whenever they discover a quality problem, as well as encourage and support problem-solving.

\subsection{Findings After Five Years}

As a result of change of leadership after slightly more than two years the focus on the lean implementation somewhat eroded. Poor profitability led to increased cost focus affecting the organizational priorities stated in the MPS; cost considerations sometimes overrode both delivery precision and quality. The newly established improvement groups were allowed to dissolve, the lean coaches in the organization were redirected to other tasks.

The experiences from earlier VFA as input for improvements to increase productivity were very good, but such analyses were scarce due to lack of resources (or allocation of resources). More use of lean tools such as SMED and VFA might have affected the balance between cost and flexibility in a positive way as increased productivity means considerably better earning capacity and flexibility. The strong cost alignment was felt to damage the long-term lean work ("what flexibility is sacrificed on account of cost focus"): e.g. not allowing enough time for improvement groups to work with time-consuming but significant issues to improve performance. As performance indicator of continuous improvements, the numbers of improvement suggestions rather than their quality or estimated effects were measured.

Three years with less focus on lean production, together with a weaker global economic development, lead to significantly reduced productivity, poor delivery performance and lower quality outcomes. When a new CEO ordered a widely conducted customer interview this resulted in competence investments in a changed and greatly strengthened management team, with renewed and strengthened focus on lean production. Internal and external communication became the first priority, and to achieve business goals by leveraging the power of improvement teams. The organization was strengthened with a human resource manager. Skills analysis and competence development became important again.

Flow planning, better asset utilization, and increased quality focus were still mentioned as most important for cost efficiency, together with total cost perspective to reduce risks. Eliminating rootcauses for firefighting, reducing wastes, and doing right from start were emphasized goals. Operators must get the chance to pull the string, which was not always encouraged in the daily work. Many more practicable improvements existed in operational performance. The rarely executed value flow analyses (VFAs) created input for continuous improvements that were very important for those kinds of cost 
efficiency activities, but to carry out VFAs more frequently would require more resources. A specialized group, complemented by personnel from the flow to be analyzed, did the VFAs.

The way of setting goals was conservative; beside the constant targets of quality, delivery precision, and productivity, concentration was still mainly on cost and economic result. Goals were however broken down for teams and improvement groups to increase understanding and improve opportunities for collaboration towards common goals. Although the values and principles of lean very much concern actions and behaviors to increase collaboration and flexibility, there were few goals to measure and follow up these.

Due to the negative economic results for a number of years, cost was of course a main concern. An increased degree of asset utilization but decreasing delivery precision might indicate a tight cost focus at the expense of flexibility. Nevertheless, to keep present customers content and to attract new customers in desired industrial segments was an overall priority. Extra efforts were made to reduce batch sizes, and shorten throughput times, in order to meet customer demands. The spread understanding of these effects and connections in the organization was an important improvement.

The most important insights and experiences after two and five years are summarized in Table 1. 


\begin{tabular}{|c|c|c|}
\hline & $\begin{array}{l}\text { After two years - } 2010 \\
\text { Insights and effects }\end{array}$ & $\begin{array}{c}\text { Findings after five years - } 2013 \\
\text { Experiences }\end{array}$ \\
\hline \multirow{3}{*}{ Context } & $\begin{array}{l}\text { Lean education shaped a broad understanding within } \\
\text { the organization. Many employees had stepped } \\
\text { forward and grown in their roles. }\end{array}$ & \multirow{2}{*}{$\begin{array}{l}\text { Changed leadership after slightly more than two years, } \\
\text { and then again after three years, eroded some of the } \\
\text { focus on the lean implementation. This and a weaker } \\
\text { global economy reduced productivity and delivery } \\
\text { performance. The increased cost focus was felt to } \\
\text { damage the long-term lean work and lower quality } \\
\text { outcomes. }\end{array}$} \\
\hline & $\begin{array}{l}\text { Changed employee attitude: understanding customer } \\
\text { demands, increased engagement and better } \\
\text { atmosphere, and greater willingness to adapt and } \\
\text { change working methods. }\end{array}$ & \\
\hline & Expectations of potential further effects & $\begin{array}{l}\text { 2013: new CEOs intentions } \\
\text { (little or no impact in the study) }\end{array}$ \\
\hline \multirow{5}{*}{$\begin{array}{l}\text { Further } \\
\text { change } \\
\text { process }\end{array}$} & $\begin{array}{l}\text { Need and possibilities for administrative } \\
\text { improvements }\end{array}$ & $\begin{array}{l}\text { Prioritizing activities for increased internal and } \\
\text { external communication. }\end{array}$ \\
\hline & $\begin{array}{l}\text { More standardization, systematization and } \\
\text { simplification in every-day activities. Standardized } \\
\text { problem solving. }\end{array}$ & $\begin{array}{l}\text { Advocating a total cost perspective: eliminating fire- } \\
\text { fighting, doing right from start, increased quality } \\
\text { focus. }\end{array}$ \\
\hline & $\begin{array}{l}\text { Operational performance priorities - cost efficiency, } \\
\text { quality ("right from me"), increased delivery } \\
\text { precision, and increased flexibility. Standardized flows } \\
\text { and stable production processes necessary. }\end{array}$ & $\begin{array}{l}\text { Leveraging the power of improvement teams. } \\
\text { Operators must get the chance to pull the string. } \\
\text { VFAs not a priority. Goals broken down for teams } \\
\text { and improvement groups. }\end{array}$ \\
\hline & $\begin{array}{l}\text { Flow planning: planning principles, visualizing } \\
\text { important flows and possibilities to increase } \\
\text { accessibility. }\end{array}$ & $\begin{array}{l}\text { To implement flow planning for better asset } \\
\text { utilization and reducing wastes. }\end{array}$ \\
\hline & $\begin{array}{l}\text { Competence, collaboration and cross-functionality, } \\
\text { required to allocate the right resources at every } \\
\text { occasion. A business strategy to coordinate the } \\
\text { resources. }\end{array}$ & $\begin{array}{l}\text { Competence investments in a strengthened } \\
\text { management team, including a HR manager for skills } \\
\text { analysis and competence development activities }\end{array}$ \\
\hline
\end{tabular}

Table 1. Comparison of the change process after two and five years

\subsection{Analyzing the Lean Implementation}

\subsubsection{Content}

The perspective of the focal supplier has changed during this time: from seeing large volumes as a necessary requirement for profitable production to accepting the idea of smaller batches as an alternative for flexible and profitable production. This illustrates well the staff's growing awareness of the changing demands when developing from component supplier to a wider role as system supplier. The ambition was to find and implement improvements that would increase efficiency and/or quality in different processes. Continuous improvements were a frequent request from several customers, and necessary to raise profitability.

The much varied orders caused shifting bottlenecks in the production flow and made the planning more difficult, but reducing the set up times (e.g. through SMED) would be one important way to increase flexibility. Many parallel processes require coordination of personnel and other resources, e.g. planning operations and supply chain performance. VFAs led to valuable suggestions from improvement groups, 
which provided both functional and cross-functional insights and increased internal collaboration. Extending supplier collaboration in competence/capacity combinations could also be practicable. Lean was seen as an important approach to improvement both in terms of cost and flexibility.

\subsubsection{Process}

The initial training for all staff was crucial for the understanding of the following process. Simulation games of stock development or of development of production bottlenecks following different planning settings contributed to a common view and a better understanding of the whole production flow. This also meant that especially the production personnel became more alert to things that hindered them from doing their best. The requirements on the administration for better planning and documentation increased.

A lean-coach for the company was introduced in order to coordinate activities and helped to spread good practice between groups and departments. This task meant to implement administrative improvements, and support standardization, systematization, simplification etc. from start, in order to establish and integrate the lean ways of working as daily routines ("the new normal"). Improvement teams were introduced and initially had much support from the lean-coach. Some of these teams, especially in the administrative functions, were cross-functional in order to also improve the overall understanding of different information- and production-processes. The introduction of morning meetings with a short debriefing of the current production situation improved communication between departments.

The production leaders for the different sections of the production department in the focal supplier had a role in between the improvement teams, the lean-coach and the CEO. As they were to different degrees convinced of the benefits of the lean implementation the question of trust and delegated authorities became an issue. A section with a dedicated production leader made a very much better progress than another section with a production leader of the "wait and see" attitude.

\subsubsection{Quality improvement measures}

Lean tools, such as 5S, SMED, and VFA, were implemented in order to try to standardize routines and stabilize processes, with built-in quality. To reduce waste in both administration and the different production steps were top priority. VFAs were appreciated by the personnel and resulted in significant improvements, but the resources to lead these analyses were scarce and very few VFA were thus carried through. 
Flow planning was a focused issue, trying to visualize important flows and to balance different customer demands. A better-balanced planning was required by many and would make it possible to increase effective production time, but the prerequisites (e.g. comprehensive maintenance of databases) for this planning situation was not that easy to accomplish.

Goals to follow up the effects of different activities were scarce; the only specific goal were the number of improvement suggestions that were carried out (though not the estimated effects of these). The middle management, especially some of the production leaders, wanted more feedback and clearer goals to work toward. They had the widened understanding of the cost - flexibility connection within the organization, and the possibilities of for example smaller batches, less goods in stock, and shorter throughput times. But despite the claims of having to optimize the value-adding flow, the productivity per machine unit still remained a highly valued performance indicator for the management.

\section{Discussion}

\subsection{Context}

Cost leadership versus differentiation (Klein, 1984) has an important strategic implication for the management: what customers and what lines of business to concentrate on? Cost efficiency often focuses on standardization, trying to optimize processes, increase the output through high asset utilization. To also combine this with a volume flexibility requires short set-up times and an efficient planning system.

All types of suppliers must fulfil basic demands such as quality and delivery precision. More specific demands on a component supplier are mainly focused on cost efficient production of a well-defined product. The demands on flexibility primarily concern volume variations, but as production is often scheduled from firm orders order size for each production batch is specified by the customer.

A system supplier must deal with a wider role. Over the years, responsibility for ever larger portions of the production chain has been outsourced to system suppliers. These need to combine efficient component production with the demands to handle volume variations as well as product flexibility. As a system supplier is expected to take part in customers' new product development processes, the request for production of initial samples and pre-series accentuate these demands. Customer forecasts are often the basis for production planning and require adaptation to rapid changes. An extensive responsibility for materials supply from suppliers all over the world makes planning complex. Different customers, active in different industries with different business logic, require efficient and parallel measures addressing both cost focus and volume variations. A system supplier strives to avoid businesses with much stressed price-focus, as the competition is too tough. Situations that are more balanced occur when long-term agreements imply 
handling and acting on forecasts. A certain level of flexibility to volume changes are then agreed upon, e.g. accepting to ramp up or down the production with a certain percentage within a few weeks. Forecast-driven lean activities may then be applied upstream the supply chain, while a more agile behavior is required for the customer orders (Naylor, Naim \& Berry, 1999; Olhager, 2003). Both cost efficiency and availability must be considered in negotiations where it is important to clarify conditions and try to raise the margins. Then it is up to the production and supply organizations to meet, challenge and improve upon these conditions, a task made easier by a lean system, with stable and standardized processes.

\subsection{Content}

These different contexts emphasize the importance of handling different flows simultaneously. The line between cost and availability focus is not distinct. To level the production, balancing the demands of different customers, is a major priority when discussing the introduction of a process-oriented flow planning system. This is also a concern of the marketing department. To choose what lines of business and what customers to work up is a true strategic matter. The risk aspects very often include cost and flexibility trade-off implications. A high price-focus for example allows no or little stock-keeping, while volume flexibility demands of quick up-ramping production may require a considerable preproduction.

The overarching goal with the lean implementation was to increase overall efficiency and eliminate waste. This was to be achieved through stable processes: to secure quality, delivery precision, and flexibility (volume and product flexibility) - cost efficiently and with higher capacity utilization. Lean production can here be seen as a foundation for more agile responses (Narasimhan et al., 2006) while requirements for flexibility without stable processes results in firefighting. Stable processes would then serve as base for continuous improvements that are a very demonstrable and sought for effect of lean as well as of agility. Well managed these improvements reduce process inefficiencies and stabilize and standardize basic capabilities.

When working closely with customers in new product development processes prototypes or pre-samples often need to be handled simultaneously with high utilization in the machines. This sometimes causes conflicts. With long set-up times for such very small batches there is a risk for delay due to previously planned serial production. One expectation from the initial lean process was increased controllability; that these conflicts would be possible to reduce or eliminate through other planning parameters. Thus, the process development for stability in the production would initially result in both higher cost-efficiency and higher flexibility. In a longer perspective, with increasing numbers of new product development processes and higher utilization of the production apparatus, this conflict would probably become intensified again (the higher the utilization rate, the more difficult to introduce new products). 
This process work was seen as a way to avoid sub-optimization and to increase the accessibility in various production groups in order to better adapt to changing customer needs. The common belief was that very much could be done by incremental changes to enhance capacity within the existing resources. Stable processes create more power and space, constituting a prerequisite for flexible processes. However, stability must not be so strictly controlled that it encroaches on flexibility, creating limitations.

"Spill-over" effects on other system capabilities are also to be expected, especially the capability of managing systems and processes. Continuous improvements are to be pursued by functional and crossfunctional teams and in processes, where embedding routines and standardizing procedures are important elements. The competitive advantage of a firm is based on the dynamics of how the firm's resources are acquired and managed. Implementing lean carefully, considering and developing the unique qualities of the organization, might lead to improvement "jumps" in performance. The pronounced organizational focus on leadership is important for this development (Adler et al., 1999; Schmenner \& Swink, 1998).

\subsection{Process}

Some actions can be identified as particularly important for this change process.

The initial focus on training all personnel resulted in a very good start of the change work. That everyone was involved increased the engagement in for example the work with $5 \mathrm{~S}$. The simulation games also meant that especially the production personnel became more alert to things that hindered them from doing their best. The requirements on the administration for better planning and documentation increased. This was an important driver for further changes.

The establishment of improvement teams was the single most important measure in the change management. But these teams had special time scheduled to work with improvement work. The result of this was that the rest of the time they worked on as usual, without thinking much on the change process. The fact that no prioritized improvement areas were clarified for the different teams and/or department or business made the improvement suggestions unfocused. The feedback (approval or rejection) concerning suggestions that the teams could not achieve by themselves should have come more quickly. Very often neither expected nor achieved effects of implemented suggestions were measured. This weakened the approach toward continuous improvement. Management support in demanding follow-ups and allowing time for testing and implementing workers' suggestions, is required.

The specific lean-coach stressed the importance of the change management and constituted an important resource in this work. But responsibility and authority for the change process became indistinct between the 
$\mathrm{CEO}$, the lean-coach and the department managers. This also contributed to an unfortunate separation of the work with the change process from the ordinary daily work of each manager and co-worker.

Tools like VFA increased the understanding of the studied process and encouraged the personnel to suggest and implement improvements (Xia \& Sun, 2013). Analyses carried out for specific product flows resulted in faster throughput and better utilization of the directly involved production resources. The staff with competence to lead a VFA worked operatively and had to focus on their daily activities. The management did not prioritize these analyses and resources were not added to systematically work through different processes. A long-term and consistent work with VFAs would probably have maintained the improvement work and contributed to the desired process approach.

Distinct goals and KPIs are important, but difficult to set and one lesson here might be to think twice about these. Lean effects are dependent upon the way people act and behave, which should be followed up. In a more long-term system supplier perspective, this would establish and promote a more agile behavior. KPIs in the focal company are chosen mostly out of routine - from what is easily measured, neglecting the more difficult soft values, such as leadership, or customer satisfaction.

To involve and engage the personnel in the process work is a key factor. The lean process with the wide training initiative created consensus, a common understanding and vision of the purpose to eliminate waste and streamline processes. VFAs, cross-functionality in some improvement teams, and translation of vision and ambition into specific goals that each co-worker can relate to may be possible ways to move from a functional way of working toward a more process-oriented approach. Management and leadership that clarify responsibilities and authorities in the organization are vital here.

When implementing lean the focus was primarily set on static efficiency and on Type I flexibility in an operational and tactical time perspective (Klein, 1984; Carlsson, 1989). For the focal SME supplier cost reduction and flexibility are not conflicting goals - they respond to customer demands and have to be met. Nevertheless, lean might function as an important eye-opener for a new outlook on productivity, an opening for the possibilities with smaller batches and shorter lead-times. This would increase the focus on strategic flexibility (Type II) with potential new customers and processes. 


\section{Conclusions}

Different customers have different demands, the business logic of some industries require outspoken cost-efficiency while others focus on high flexibility. Either way, the basic demands for correct quality and delivery precision require stable processes. This process approach is by the focal supplier considered as a necessary first step for the transition to system supplier. Stable and standardized processes also allow for new combinations of capabilities and may be a step to contribute to competitive value through better operational performance or enhanced supplier collaboration.

The answer to the research question is consequently yes: Yes, implementation of lean would improve the capabilities of a SME supplier to meet basic demands and add system supplier capabilities, especially focusing cost efficiency and flexibility. Increasing operational performance (quality, delivery, cost, flexibility) certainly helps improving the system capabilities of managing generic demands. Stable and effective processes, resulting in dependable quality and delivery times, reduce the cause for urgent corrective measures and increase the effective production time. This provides the production planning better opportunities to succeed in the next step. To meet the demands of cost-efficiency and flexibility on a basic level creates no conflict, and the achieved stability would be a stepping stone for continuous improvements.

\subsection{Lean or Agile}

The study thus clearly suggests that there is a need for a basic stability in the organization before it is necessary to choose between a lean or agile strategy. In the case of this company this was done by a lean approach. The tools that mainly was used were focused on change management, (lean coaches and improvement teams) which is the process dimension of change (Pettigrew, 1987). Efficient methods for change management are not necessarily related to questions related to strategies and content. In this case the conclusion is that the change methods worked well.

An appreciated method for analyzing and improving the content of a work flow in the company was value flow analysis. The method is basically an analytical tool, not saying anything about how a business should be organized. In a method of analysis there is of course always an assumption of what is wanted. In the case of VFA the goal is process orientation. Process orientation however seems to be beneficial for both increased cost efficiency and flexibility. The conclusion based on this study is therefore that process orientation in itself is not typical for lean, it is rather the basis for both lean and agile approaches.

If the company further develops it might be that there is a choice that has to be made to further develop between, flexibility (agile) or cost efficiency (lean). During the first five years the choice was not present. 
This suggests that process orientation of a company is more important in early stages of a company's development than the discussion of lean or agile.

As shown in the case study different contexts, that is different demands in different markets, are great. Some markets focus on cost efficiency and some on flexibility. There are also different demands in the same market in different parts of the production cycle. There are more explicit demands on flexibility in the pre-production phase than during the volume production phase.

This suggests that if, or when, the company have to choose between lean and agile it is also necessary to decide between which market segments to keep and which to leave depending on demands on services required.

In conclusion the study suggests there is a basic level of process orientation that has to be achieved before there is a need to consider a lean or agile approach to organizing the business. In this study the basic components of a process orientation found necessary are:

- Leaders with a holistic view of workflow in the company, capable of setting and distributing clear goals, and supporting competence development and a climate of trust

- Internal and external communication for increased collaboration and cross-functionality

- Flow planning capability for increased flexibility

\section{Further Research}

This is a single case study mainly about the expectations on lean production. An interesting potential to investigate would be to find examples of how lean has helped SME subcontractors to shape and use capabilities strategically to form attractive customer offers.

\section{References}

Adler, P.S., Goldoftas, B., \& Levine, D.I. (1999). Flexibility versus Efficiency? A Case Study of Model Changeovers in the Toyota Production System. Organization Science, 10(1), 43-68.

https://doi.org/10.1287/orsc.10.1.43

Bhasin, S., \& Burcher, P. (2006). Lean viewed as a philosophy. Journal of Manufacturing Technology Management, 17(1), 56-72. https://doi.org/10.1108/17410380610639506 
Carlsson, B. (1989). Flexibility and the theory of the firm. International Journal of Industrial Organization, 7(2), 179-203. https://doi.org/10.1016/0167-7187(89)90018-0

Clark, K.B. (1996). Competing through manufacturing and the new manufacturing paradigm: Is manufacturing strategy passé?. Productions and Operations Management, 5(1), 42-58. https://doi.org/10.1111/j.1937-5956.1996.tb00384.x

Hallgren, M., \& Olhager, J. (2009). Lean and agile manufacturing: external and internal drivers and performance outcomes. International Journal of Operations \& Production Management, 29(10), 976-999. https://doi.org/10.1108/01443570910993456

Hayes, R.H., \& Pisano, G.P. (1996). Manufacturing strategy: at the intersection of two paradigm shifts. Productions and Operations Management, 5(1), 25-41. https://doi.org/10.1111/j.1937-5956.1996.tb00383.x

Hines, P., Holweg, M., \& Rich, N. (2004). Learning to evolve, A review of contemporary lean thinking. International Journal of Operations \& Production Management, 24 (10), 994-1011.

https://doi.org/10.1108/01443570410558049

Klein, B.H. (1984). Prices, wages and business cycles: A dynamic theory. New York: Pergamon.

Levinthal, D.A., \& March, J.G. (1993). Myopia of learning. Strategic Management Journal, 14(S2), 95-112. https://doi.org/10.1002/smj.4250141009

March, J.G. (1991). Exploration and exploitation in organizational learning. Organization Science, 2(1), 71-87. https://doi.org/10.1287/orsc.2.1.71

Meade, L.M., \& Sarkis, J. (1999). Analyzing organizational project alternatives for agile manufacturing processes: An analytical network approach. Journal of Production Research, 37(2), 241-261. https://doi.org/10.1080/002075499191751

Narasimhan, R., Swink, M., \& Kim, S.W. (2006). Disentangling leanness and agility: An empirical investigation. Journal of Operations Management, 24, 440-457. https://doi.org/10.1016/j.jom.2005.11.011

Naylor, B.J., Naim, M.M., \& Berry, D. (1999). Leagility: Integrating the lean and agile manufacturing paradigms in the total supply chain. International Journal of Production Economics, 62, 107-118. https://doi.org/10.1016/S0925-5273(98)00223-0

Olhager, J. (2003). Strategic positioning of the order penetration point. International Journal of Production Economics, 85, 319-329. https://doi.org/10.1016/S0925-5273(03)00119-1 
Pettigrew, A.M. (1987). Context and action in the transformation of the firm. Journal of Management Studies, 24(6), 649-670. https://doi.org/10.1111/j.1467-6486.1987.tb00467.x

Schmenner, R.W., \& Swink, M.L. (1998). On theory in operations management. Journal of Operations Management, 17, 97-113. https://doi.org/10.1016/S0272-6963(98)00028-X

Skinner, W. (1996). Manufacturing Strategy on the "S" curve. Production and Operations Management, 5(1), 3-14. https://doi.org/10.1111/j.1937-5956.1996.tb00381.x

Sugimori, Y., Kusunoki, K., Cho, F., \& Uchikawa, S. (1977). Toyota production system and Kanban system. Materialization of just-in-time and respect-for-human system. International Journal of Production Research, 15(6), 553-564. https://doi.org/10.1080/00207547708943149

Vastag, G. (2000). The theory of performance frontiers. Journal of Operations Management, 18, 353-360. https://doi.org/10.1016/S0272-6963(99)00024-8

Xia, W., \& Sun, J. (2013). Simulation guided value stream mapping and lean improvement: A case study of a turbular machining facility. Journal of Industrial Engineering and Management, 6(2), 456-476.

http://dx.doi.org/10.3926/jiem.532

Zhang, Q., Vonderembse, M.A., \& Lim, J-S. (2005). Logistics flexibility and its impact on customer satisfaction. The International Journal of Logistics Management, 16(1), 71-95.

https://doi.org/10.1108/09574090510617367

Journal of Industrial Engineering and Management, 2017 (www.jiem.org)

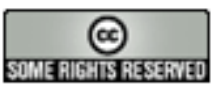

Article's contents are provided on an Attribution-Non Commercial 3.0 Creative commons license. Readers are allowed to copy, distribute and communicate article's contents, provided the author's and Journal of Industrial Engineering and Management's names are included. It must not be used for commercial purposes. To see the complete license contents, please visit http://creativecommons.org/licenses/by-nc/3.0/. 